\title{
The locative alternation: Distinguishing linguistic processing cost from error signals in Broca's region
}

\author{
Ken Ramshøj Christensen a,b,*, Mikkel Wallentin ${ }^{\mathrm{a}, \mathrm{c}}$ \\ a Center for Functionally Integrative Neuroscience, Aarhus University, Denmark \\ b Institute for Language, Literature and Culture, Aarhus University, Denmark \\ c Center for Semiotics, Aarhus University, Denmark
}

\section{A R T I C L E I N F O}

\section{Article history:}

Received 7 October 2010

Revised 16 February 2011

Accepted 19 February 2011

Available online 6 March 2011

\begin{abstract}
A B S T R A C T
The left inferior frontal gyrus (LIFG) is known to be involved in the processing of syntactic complexity, such as word order variation. It is also known to be involved in semantic interpretation in studies of various types of semantic and pragmatic anomalies. Across neuroimaging studies of language processing, two main approaches can be found, one that contrasts anomalous and well-formed words or sentences in order to yield an error response and one that contrasts two well-formed syntactic structures differing in complexity, investigating effects of increased integration costs. The present fMRI study aimed at disentangling the error signal from the processing cost signal in LIFG. To do so, we examined the so-called Locative Alternation, which involves the contrast between the Content-Locative construction, e.g. He sprays paint on the wall, and the Container-Locative construction, e.g. He sprays the wall with paint, which have been argued to differ in processing. By including asymmetric verbs, e.g. He blocks the road with rocks vs. *He blocks rocks on the road, we were able to study the contrast between well formed and anomalous constructions. Participants performed an acceptability judgment task during fMRI. The results showed that increased syntactic integration costs yielded both increased response time as well as LIFG activation. Anomalous sentences yielded low acceptability rating but no increase in response time, yet they also evoked increased LIFG activation. Thus, the processing cost and the error signal were found to be functionally independent, but spatially overlapping in the brain.
\end{abstract}

(c) 2011 Elsevier Inc. All rights reserved.

\section{Introduction}

The left inferior frontal gyrus (LIFG) is known to be crucial to various types of language processing. In particular, it has been shown numerous times with fMRI and PET that LIFG is involved in the processing of certain types of syntactic complexity, for example word order variation, structural ambiguity, and clausal embedding (BenShachar et al., 2003; Ben-Shachar et al., 2004; Christensen, 2008, 2010; Fiebach et al., 2004; Fiebach et al., 2005; Friederici et al., 2006; Grewe et al., 2005; Inui et al., 1998; Just et al., 1996; Mason et al., 2003; Röder et al., 2002; Stowe et al., 1998; Stromswold et al., 1996).

LIFG is also known to be involved in semantic interpretation, at least judging from the studies of various types of semantic and pragmatic anomalies, e.g. She poured herself a nice glass of lemonade/?sugar/*rocks, using fMRI (Baumgaertner et al., 2002; Cardillo et al., 2004; Hagoort et al., 2004; Kuperberg et al., 2003; Willems et al., 2007), as well as ERP studies (Friederici, 2002; Friederici et al., 2003; Hagoort et al., 2004; Kutas and Hillyard, 1980; Osterhout and Nicol, 1999; Saddy et al., 2004a,b), and MEG (Halgren et al., 2002; Maess et al., 2006). Though the ERP effect of

\footnotetext{
* Corresponding author at: Institute for Language, Literature, and Culture, Aarhus University, Jens Chr. Skous Vej 5, DK-8000 Aarhus C, Denmark.

E-mail address: KenRC@hum.au.dk (K.R. Christensen).
}

semantic anomaly, the $\mathrm{N} 400$, is centered over the parietal lobe, Halgren et al. (2002) report the LIFG to contain one of the generators of the N400.

It has also been argued that LIFG can be divided into two or three functional subcomponents responsible for different linguistic processes. The posterior superior part, pars opercularis (taken to correspond to Brodmann area (BA) 44), is involved in syntactic processing, whereas the anterior inferior pars triangularis (corresponding to BA 45) and pars orbitalis (corresponding to BA 47) are involved in thematic integration and lexical semantic processing, respectively (e.g. Bookheimer, 2002; Dapretto and Bookheimer, 1999; Fiebach et al., 2005; Friederici, 2002; Newman et al., 2003; but see Lindenberg et al., 2007).

There is an interesting difference between the kinds of studies typically used to localize syntactic processing and those used for localizing semantic integration, at least in the fMRI literature. In neuroimaging studies on syntax, usually two well-formed syntactic structures differing in complexity are contrasted. The results, the differential neural activity levels, are then attributable to the difference in processing. Anomaly studies, on the other hand, typically use oddball design in which anomalous strings are contrasted with non-anomalous strings. The activation triggered by the anomaly is then taken to reflect semantic processing in general. That is, the error signal induced by the anomaly is taken to be an exaggerated version of the processing signal of the non-anomalous. 
The present study aimed at disentangling the error signal (induced by a semantic anomaly) from the processing signal (induced by a syntactic contrast). To do so, we examined the so-called locative alternation, also known as the spray/load alternation (Arad, 2005; Kemmerer, 2003; Kemmerer and Gonzalez-Castillo, 2010; Levin, 1993; Pinker, 1989, 2007). A ditransitive verb is one that takes two objects, e.g. Jack gave his wife a present. Some ditransitive verbs, however, take a noun phrase (NP) object and a prepositional phrase (PP). A subclass of these constructions contains verbs of caused motion, meaning something like 'causing $\mathrm{x}$ to go to $\mathrm{y}$ '; some of these verbs, e.g. spray and load, are 'alternating' in the sense they allow their two objects to occur in two orders: (i), Verb $\mathrm{NP}_{1}$ [pP Prep $\mathrm{NP}_{2}$ ], e.g. Jack sprayed paint on the wall, called the Content-Locative variant because the 'content', the NP with the thematic role of THEME, precedes the locative PP containing the NP assigned the role of GOAL; (ii), Verb $\mathrm{NP}_{2}$ [ ${ }_{\mathrm{PP}}$ Prep $\mathrm{NP}_{1}$ ], e.g. Jack sprayed the wall with paint, called the ContainerLocative because the 'container/surface', the GOAL NP, precedes the locative PP containing the THEME NP.

The meaning of the Content-Locative construction is built on the following frame: 'AGENT cause THEME to go to GOAL' (to load the truck with crates means causing the crates to go onto the truck), while the meaning of the Container-Locative construction is based on: 'AGENT cause GOAL to change state by causing THEME to go to GOAL' (to load the truck with crates means changing the state of the truck, i.e. filling it, by moving the crates onto the truck). Interestingly, only some of these verbs, such as spray and load, can be used both in the Content-Locative and Container-Locative constructions, whereas others, due to semantic constraints, can only be used in one or the other construction (e.g. pour and cover). We shall refer to verbs that allow both constructions, i.e. verbs that are fully alternating as type $A$. The non-alternating verbs that only allow the Content-Locative construction (John poured water into the bowl, but not *John poured the bowl with water), we shall refer to as type B. Conversely, the non-alternating verbs that only allow the Container-Locative construction (*Jack covered the blanket over the baby, but Jack covered the baby with blanket), we shall refer to as type $\mathrm{C}$. Whether a verb is type A, B, or C depends on its lexical semantics; pour does not refer to any qualitative changes in the state of the container (fill does), and cover cannot be used to designate caused motion (move can). We shall refer to the Content-Locative construction as construction 1 and the Container-Locative as construction 2. With this we are able to make six types of sentences (A1, A2, B1, B2*, $\mathrm{C}^{*}$, and $\mathrm{C} 2$; see Table 1 and Supplementary material for a complete list). Note, that constructions B2 and $\mathrm{C} 1$ result in anomalous/ ungrammatical sentences, as indicated with the asterisks $\left(^{*}\right.$ ) (see Methods section for details).

As mentioned above, word order variation has been found to increase activation in LIFG. However, word order variation in itself

\section{Table 1}

Stimulus examples. In type A, both constructions, the Content-Locative and the ContainerLocative, are well-formed. Type B is only compatible with the Content-Locative, whereas type $\mathrm{C}$ is only compatible with the Container-Locative (the asterisk * indicates anomaly/ ungrammaticality) (see Supplementary material for a complete list of sentences).

\begin{tabular}{lll}
\hline \multirow{2}{*}{ Type } & Construction & \\
\cline { 2 - 3 } & 1: Content-Locative & 2: Container-Locative \\
\hline A & Han fylder jord i hullet & Han fylder hullet med jord \\
& $\begin{array}{l}\text { He fills dirt in hole-the } \\
\text { Han fylder bagage på båndet }\end{array}$ & He fills hole-the with dirt \\
& He fills luggage on band-the & He fills band-the with luggage \\
B & Han kaster græs i vandet & *Han kaster vandet med græs \\
& He throws grass in water-the & He throws water-the with grass \\
& Han kaster sne på døren & *Han kaster døren med sne \\
& He throws snow on door-the & He throws door-the with snow \\
C & *Han blokerer skrald i afløbet & Han blokerer afløbet med skrald \\
& He blocks garbage in drain-the & He blocks drain-the with garbage \\
& *Han blokerer sten på vejen & Han blokerer vejen med sten \\
& He blocks rocks on road-the & He blocks road-the with rocks \\
\hline
\end{tabular}

need not increase activation in LIFG (Christensen, 2008). According to the Linearization Hypothesis (Bornkessel et al., 2005), the crucial factor is whether the linear order of constituents matches their relative order in a thematic hierarchy, for example, AGENT > EXPERIENCER>THEME $>$ GOAL; the AGENT role is thought to be semantically more salient than the EXPERIENCER, etc. It is widely assumed that the thematic hierarchy is also reflected in the syntactic structure; that is, more salient roles, such as AGENT, are usually merged higher in the structure, less salient roles, e.g. THEME, lower (e.g. Baker, 1997; Larson, 1988). In addition, in languages such as English and German, there is a preference for having the subject precede the object (subject>object); in the absence of contradicting evidence, the first noun phrase in a sentence will be interpreted as the subject of the clause. According to Bornkessel et al. (2005), when the linear word order violates one or both of these hierarchies (AGENT $>$ EXPERIENCER $>$ THEME $>$ GOAL and subject $>$ object), the activation in LIFG increases. In other words, LIFG is predicted to show an effect reflecting the complexity of crossed mapping (see Fig. 1). This hypothesis accounts for the typical object-before-subject examples, such as object relatives, object questions, object topicalization, in which the fronted object is usually the THEME and the subject is the AGENT (e.g.

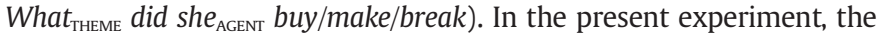
Locative Alternation also involves crossed mapping, as illustrated in Fig. 1. By hypothesis, the contrast between the two constructions should result in differential LIFG activation. The Container-Locative should thus increase LIFG activation relative to the Content-Locative due to the increased cost of integrating a non-standard linearization of the thematic hierarchy.

Our study was based on three research questions:

Question one: Is there a BOLD response in LIFG, in particular pars opercularis, reflecting syntactic processing due to the difference in syntactic structure between the two constructions $(1,2)$ ? Such an effect would be the result of contrasting the Content-Locative and the Container-Locative $(1>2,2>1)$ across the three types (i.e. A, B, and C), and more particularly when contrasting A1 and A2 (both acceptable). According to the hypothesis of Bornkessel et al. (2005), crossed mapping between word order and the order of thematic roles in the thematic hierarchy should trigger LIFG.

Question two: Do anomalous conditions (B2* and $\mathrm{C} 1^{*}$ ) in themselves trigger LIFG, in particular pars triangularis (and perhaps also pars orbitalis)? If so, the effect should result from the interaction between construction $(1,2)$ and type (A, B, C), and even more so, it should be the main effect of anomaly (contrasting anomalous and non-anomalous in types B and C). As mentioned in the beginning, such an effect is predicted from a number other studies of linguistic anomalies. For example, Hagoort et al. (2004) report from a study on semantic and world-knowledge

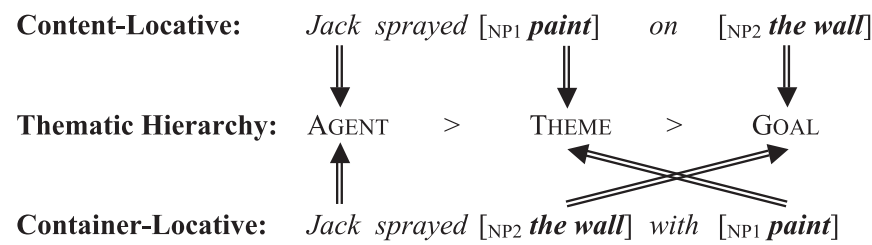

Fig. 1. Mapping between the order of thematic roles in two constructions of the Locative Alternation and the ranking order of the thematic hierarchy. Note that the mapping between the Content-Locative and the thematic hierarchy is straightforward, whereas the mapping is crossed between the Container-Locative and thematic hierarchy. 
violations in Dutch. They presented participant with well-formed examples, such as The Dutch trains are yellow and very crowded, which happens to be true, semantically anomalous sentences, The Dutch trains are sour and very crowded, and examples that violated the Dutch participants' knowledge about Dutch trains, The Dutch trains are white and very crowded (The trains are in fact yellow). The semantically anomalous sentences (sour trains) increased activation in LIFG, but so did the worldknowledge violations (white trains), even though they were linguistically completely well-formed. Hagoort et al. (2004) interpret the result as reflecting the relative cost of the integration of yellow/sour/ white into the semantic representation. Cardillo et al. (2004) studied semantically incongruent sentences, such as Pasta is my favourite kind of ball, and found that they increased activation in LIFG relative to controls. They argue that LIFG inhibits interference from prepotent representations (which would be, e.g. favourite kind of food) in order to select a taskappropriate target (i.e. favourite kind of ball).

Question three: Can the error signal be disentangled from the processing signal? That is, is there a difference between the localization of a potential effect of construction type and a potential anomaly effect, or are they indistinguishable? The assumption underlying the use of oddball paradigms to locate, say, semantic or syntactic processing is that they are the same. The anomaly effect is taken to be an exaggerated version of the normal effect, which in fact also seems to be the case in ERP. However, it need not be the case in fMRI since the BOLD signal is on a different time scale and may have different triggers.

\section{Methods \\ Participants}

22 (12 female) right-handed, normal native speakers of Danish (mean age 24.2 years, range: $19-37$, std. 5.33 ) participated in the experiment. Gender was not considered in this experiment (Wallentin, 2009). Written consent was given prior to participation. Ethical approval for the experiment was acquired from The Central Denmark Region Committees on Biomedical Research Ethics.

\section{Materials}

A total of 96 sentences were constructed (16 sentences $\times 3$ types $\times 2$ constructions), all five words long, all with the pronoun han 'he' as the subject and a verb in present tense followed by an NP and a PP. The Content-Locative constructions were constructed in two ways, one with the preposition $i$ 'in' and one with på 'on'. All Container-Locatives contained a PP headed by the preposition med 'with'.

Sentences for the auditory session were recorded in a male, neutral voice. All sentences lasted exactly two seconds. During the visual session, sentences were also displayed for two seconds each (Fig. 2). Due to unexpectedly low acceptability-ratings, two sentences, one from $\mathrm{A} 2$ and one from $\mathrm{B} 1$, both rated in the visual session, were excluded from analysis. (On visual vs. auditory sessions, see the Procedure section below; for a complete list of stimulus sentences, including the two excluded ones, see Supplementary material.)

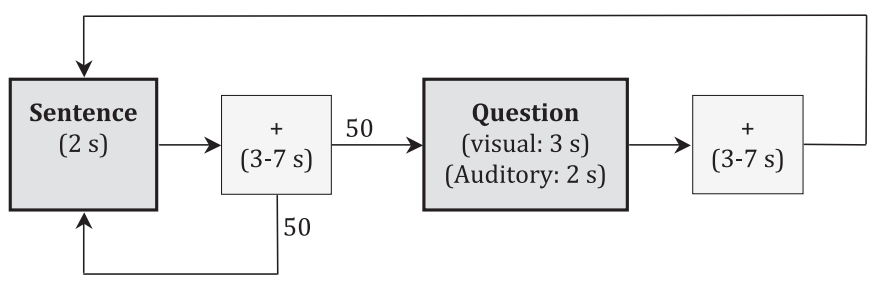

Fig. 2. Participants encountered sentences in two sessions. In the first session sentences were presented on a screen. After a $3-7 \mathrm{~s}$ interval there was a $50 \%$ chance that the response cue "Did it make sense" would be presented through headphones and a $50 \%$ chance that the next sentence would be presented. In the case of a response cue the next target sentence would follow after another 3-7 s interval. In this way brain activation due to responding was orthogonal to brain activation due to sentence processing. The second session presented sentences verbally and response cues visually. This enabled an analysis of linguistic processing disentangled from perceptual modality.

\section{Procedure}

All sentences were presented twice during the experiment, once for each of two scanning sessions. In the first session participants read the sentences on a screen, placed at the end of the scanner bed. Stimuli were projected onto the screen using a video projector standing in the control room. Sentences were viewed trough the mirror mounted on the head coil. In the second session participants heard the sentences through pneumatic headphones (Avotec). The task in both sessions was to judge whether or not the sentences made sense. Participants responded with a button press (right index finger for "yes" and right middle finger for "no"). In order to be able to separate linguistic processing from motor output, participants only judged half of the sentences in each session. The cue to respond was given in the opposite modality of the input sentence, i.e. in the first session this cue was presented through the headphones and in the second session it was presented in written form. In both cases the cue was always the sentence: Gav det mening? (“Did it make sense?"). The cue question was presented after a random 3-7 s interval (Fig. 2) and after the question a new sentence was presented after another 3-7 s interval. In the cases where no question was presented the next sentence came on after the initial 3-7 s interval (see Fig. 2).

The order of sentences was randomized both across sessions and participants, but participants always responded to the same sentences during the visual and the auditory sessions, half from each verb type.

This design has the advantage of being able to collect acceptability ratings continuously through the experiment without the risk of contaminating the sentence comprehension data with motor processes. In order for response time to be comparable across participants, the sentences rated in each session were always the same (i.e. sentences 1-8 from conditions $A, B$, and $C$ in the visual session, and sentences 9-16 from A, B, and C in the auditory session).

All stimuli and responses were presented and collected using Cogent 2000 running in Matlab (Mathworks Inc., Sherborn, MA, USA). Cogent 2000 is developed by the Cogent 2000 team at the Functional Imaging Laboratory and the Institute of Cognitive Neuroscience, UCL, London.

Functional MR images were acquired on a General Electrics 3 Tesla system using a standard head coil. Scans were performed using an echo planar imaging sequence with a flip angle $=90, \mathrm{TE}=30$, and $\mathrm{TR}=2200 \mathrm{~ms}$. Each volume consisted of 44 axial slices covering the entire cerebrum and cerebellum (slice thickness $=3.3 \mathrm{~mm}$, spacing $=0, \mathrm{FOV}=21.1 \mathrm{~cm})(64 \times 64$ inslice voxels $) .375$ volumes were acquired in the visual session, 355 in the auditory.

\section{Data analysis}

Behavioral variables were analyzed using a repeated measures ANOVA script for MatLab written by Richard Henson (Cambridge 
University) incorporating a Greenhouse-Geisser correction of the degrees of freedom in the case of measured non-sphericity.

The fMRI data was analyzed with SPM8 (Wellcome Department of Imaging Neuroscience, University College London). The imaging data were realigned, normalized (reslicing the voxels to $2 \times 2 \times 2 \mathrm{~mm}$ ), and smoothed ( $8 \mathrm{~mm}$ FWHM). All events were modeled using the standard hemodynamic response function of SPM8 with durations of $3 \mathrm{~s}$ for visual stimuli and $2 \mathrm{~s}$ for auditory stimuli (see Fig. 2). Questions and responses were modeled with a separate regressor. Data from the latter are not reported.

The model was estimated for each participant using a general linear model with a 128-s high-pass filter, and AR(1) modeling of serial correlation, before being submitted to a second level, randomeffect analysis. This was conducted as a three-way repeated measures whole brain ANOVA in SPM8. Individual subject effects were modeled using the "covariate" function. We did not assume independence or equal variance. Instead co-variance components were used to adjust the statistics and degrees of freedom during inference. ANOVA effects were explored using t-contrasts. Since our analyses were focused on the left inferior frontal gyrus, we subsequently conducted a region of interest analysis in this region (see Introduction) using the same model. All imaging results are corrected for multiple comparisons $(p<0.05, \mathrm{FWE})$.

Following up on the initial analysis we conducted a parametric analysis using individual response time and average acceptability ratings for each sentence as covariates of interest (see Supplementary material for a complete list of sentences with acceptability and response time measures). Due to differences in response times for the visual and auditory sessions (see above and Behavioral results section), response times were corrected for this before being used in the parametric analysis. Thus, response times obtained in both sessions were used in the analyses of both sessions. The resulting beta estimates for each session were subsequently averaged and submitted to two one-sample $t$-test random effects analyses (one for acceptability and one for response time). Again, we applied a left inferior frontal gyrus region of interest mask before correcting for multiple comparisons $(p<0.05$, FWE).

\section{Results}

\section{Behavioral results}

\section{Acceptability}

A three-way repeated measures ANOVA with perceptual modality (visual, auditory), verb type (A, B, C), and construction type $(1,2)$ as input factors revealed the following results on acceptability judgments: a significant main effect of verb type $(F(1.80,37.72)=292.334$, $\mathrm{p}<0.001)$, no effect of construction type $(\mathrm{F}(1.00,21.00)=1.173$, $p=0.291)$ and no effect of modality $(F(1.00,21.00)=0.013$, $p=0.910)$, but a significant interaction between verb type and construction $(\mathrm{F}(1.36,28.60)=501.616, p<0.001)$. All other interaction effects were non-significant $(p>0.26)$. (All significant $p$-values are Bonferroni-corrected.)

The main effect of verb type was caused by verb type A overall having a larger acceptability rate (89.8\%) than type B (52.8\%) and C (54.5\%). (In type A, both constructions are possible, whereas in B and $\mathrm{C}$, one of the two constructions is anomalous.)

The most clearly observable effect, however, was the interaction between verb type and construction type (note the large F-value). This was the expected effect caused by type B verbs not being suitable for the Container-Locative construction (type 2, see Fig. 1 and Table 1) while type $C$ verbs cannot be used within the Content-Locative construction (type 1). Given that there was no effect of modality, planned pair-wise t-tests collapsed visual and auditory modalities. These tests revealed no significant difference between A1 and A2 ( $t$ $(21)=0.23 ; p=0.82)$, a significant difference between B1 and B2 $(\mathrm{B} 1>\mathrm{B} 2, \mathrm{t}(21)=18.78 ; p<0.001)$ and a significant difference between $\mathrm{C} 1$ and $\mathrm{C} 2(\mathrm{C} 2>\mathrm{C} 1, \mathrm{t}(21)=-25.26 ; p<0.001)$ (significant $p$-values Bonferroni-corrected), see Fig. 3 and Table 2.

\section{Response time}

Another three-way repeated measures ANOVA on response times revealed significant main effects of modality $(F(1.00,21.00)=105.886$, $p=0.000)$, verb type $(\mathrm{F}(1.69,35.42)=5.447, p=0.012)$ and construction type $(\mathrm{F}(1.00,21.00)=17.736, p=0.000)$. There were also significant interaction effects, namely, modality $\times$ verb type $(F(1.80,37.73)$ $10.531, p=0.000)$, and modality $\times$ verb type $\times$ construction ( $F$ $(1.41,29.69)=5.163, p=0.020)$. The remaining two interaction effects, i.e. modality $\times$ construction and verb type $\times$ construction, were not significant $(p>0.23)$.

Exploring the main effect of construction type revealed that construction 2 had a longer response time (average $=1021 \mathrm{~ms}$ ) than construction 1 (945 ms). This difference was also significant when comparing only constructions in the A sentence condition $(A 2>A 1, t(21)=4.67, p<0.001)$ where there were no significant differences in sentences acceptability judgments. There were no significant differences between B1 and B2* $(\mathrm{t}(21)=1.88, p=0.07)$, and $\mathrm{C}^{*}$ and $\mathrm{C} 2(\mathrm{t}(21)=0.19, p=0.85)$, see Fig. 3 and Table 2 .

We performed a multilinear regression of the average response times across participants for each sentence on the acceptability ratings (percentage of participants who rated them as meaningful during scanning). The model included both a quadratic and a linear term and data were corrected for whether sentences had been rated in the visual or auditory session. The F-statistics showed that the model
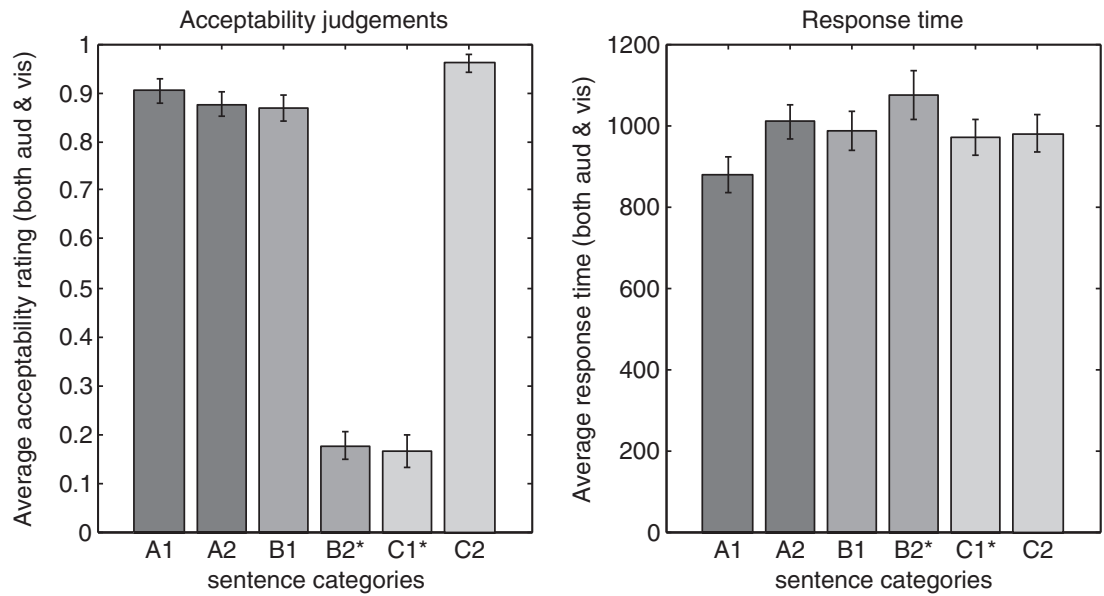

Fig. 3. Behavioral results. Left: Acceptability judgments, right: Response times. 
Table 2

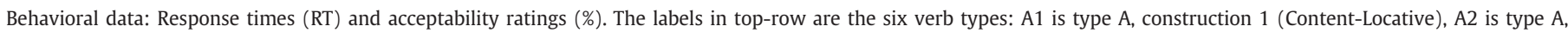
construction 2 (Container-Locative); cf. Table 1. An asterisk $\left({ }^{*}\right)$ indicates an anomalous verb type.

\begin{tabular}{|c|c|c|c|c|c|c|}
\hline & $\mathrm{A} 1$ & $\mathrm{~A} 2$ & B1 & $\mathrm{B} 2^{*}$ & $\mathrm{C} 1^{*}$ & $\mathrm{C} 2$ \\
\hline \multicolumn{7}{|l|}{ Visual modality } \\
\hline $\mathrm{RT}(\mathrm{ms}) \pm \mathrm{std}$ & $1078 \pm 259$ & $1210 \pm 229$ & $1211 \pm 346$ & $1178 \pm 235$ & $1021 \pm 172$ & $1076 \pm 259$ \\
\hline Acceptability (\%) \pm std & $90.3 \pm 11.5$ & $87.7 \pm 11.1$ & $86.8 \pm 12.4$ & $17.6 \pm 13.2$ & $16.5 \pm 15.1$ & $96.0 \pm 8.1$ \\
\hline \multicolumn{7}{|l|}{ Auditory modality } \\
\hline $\mathrm{RT}(\mathrm{ms}) \pm \mathrm{std}$ & $681 \pm 187$ & $806 \pm 210$ & $760 \pm 186$ & $973 \pm 418$ & $918 \pm 291$ & $884 \pm 219$ \\
\hline Acceptability $(\%) \pm$ std & $89.8 \pm 10.1$ & $91.5 \pm 11.8$ & $89.2 \pm 12.4$ & $17.6 \pm 18.4$ & $17.1 \pm 18.7$ & $88.6 \pm 10.9$ \\
\hline
\end{tabular}

explained a significant part of the variance $(\mathrm{F}(2,91)=30.8 ; p<0.0001$; $\left.\mathrm{R}^{2}=0.40\right)$. Subsequent t-tests showed that both the quadratic $(\mathrm{t}(91)$ $7.2, p<0.001)$ and linear $(\mathrm{t}(91)=6.4, p<0.0001)$ terms contributed significantly to the effect (Fig. 4). This shows that both very easily understandable (i.e. non-anomalous) and clearly anomalous sentences have shorter response latencies than sentences that are slightly more ambiguous.

\section{fMRI results}

\section{Whole brain results}

In the group analysis, we found a main effect of modality. The reading task evoked a significantly greater BOLD response in primary and secondary visual regions whereas the listening task evoked a significantly larger response in auditory cortices (see Table 3; Fig. 5).

A main effect of construction type (construction 2: ContainerLocative $>$ construction 1: Content-Locative) was found in LIFG pars triangularis (Table 3). An interaction between verb type and construction type was found in a network of regions including most significantly LIFG pars triangularis, but also the supplementary motor

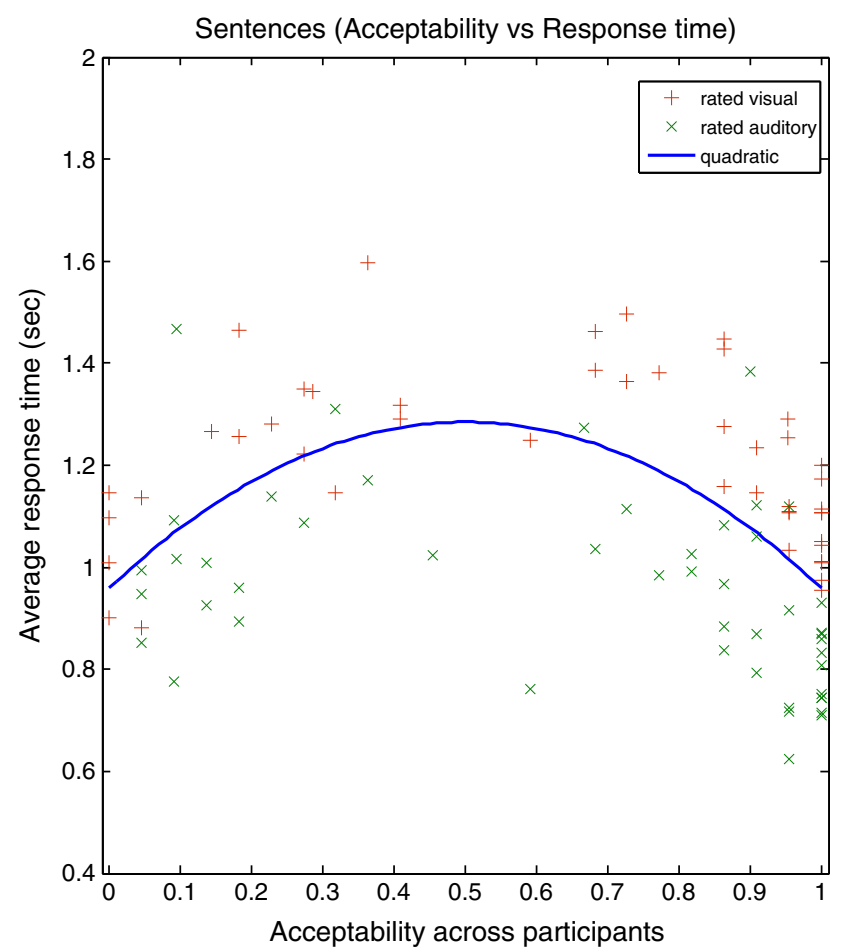

Fig. 4. Multi-linear regression with overall scores of each sentence as input. A quadratic relationship between acceptability and RT across participants is demonstrated. Sentences marked ' + ' were rated in the reading session by all participants. In this session the response cue was presented through headphones. Sentences marked ' $x$ ' were rated in the listening session. In this session response cues were presented visually. The latter yielded an overall shorter RT which was filtered out prior to the regression analysis. area (SMA), premotor structures and middle temporal cortex. This effect was driven by the main effect of anomaly (i.e. $\left(B 2^{*}+C 1^{*}\right)>(B 1$ C2)) shown in Fig. 7. Given the hypothesis about the subdivision of LIFG mentioned in the Introduction, we applied an analysis of the cluster using automated anatomical labeling (AAL) (Tzourio-Mazoyer et al., 2002) to the large cluster (1980 voxels of $2 \times 2 \times 2 \mathrm{~mm}$ ) with local maxima in LIFG. This analysis revealed that $54 \%$ of the voxels were located in pars triangularis, $15 \%$ in pars opercularis, and $8 \%$ in pars orbitalis (the remaining $23 \%$ in the insula, midfrontal, and precentral gyri).

In addition, we also found a surprising interaction between perceptual modality and verb type in the left amygdala (Table 3), primarily driven by verb type A for some reason showing more activation in the visual session than in the auditory one. No other main effects or interactions were observed.

\section{Region of interest: Inferior frontal gyrus}

Given the specificity regarding the hypothesis about the involvement of the left inferior frontal gyrus, a region of interest (ROI) analysis was applied using the WFU (Wake Forest University School of Medicine) Pickatlas (Maldjian et al., 2004, 2003) referencing in the AAL atlas (Tzourio-Mazoyer et al., 2002). The ROI comprised the pars opercularis, pars triangularis, and pars orbitalis. When restricting the search to this ROI ( $p<0.05$, FWE-corrected for multiple comparisons), we found a main effect of construction (construction $2>$ construction 1 ), namely, two clusters with a peak in pars triangularis and one with a peak in pars opercularis (Table 3, Fig. 7). Partitioning of the largest cluster (144 voxels, $1152 \mathrm{~mm}^{3}$, peak in pars triangularis) using automated anatomical labeling (Tzourio-Mazoyer et al., 2002) revealed that $93 \%$ of this cluster was in pars triangularis, $7 \%$ in pars opercularis. However, the clusters in pars triangularis and pars opercularis shows the same overall activation pattern, i.e. the verb type $\times$ construction interaction shown in Fig. 6 .

No other significant effects or interactions were observed that were not also found in the whole brain analysis.

The parametric analyses revealed that across all sentences, there is a significant effect of acceptability in LIFG mirroring the effect found for anomalous sentences and an effect of response time mirroring the main effect of construction (Fig. 7, Table 4).

\section{Discussion}

The study was based on three basic research questions. Question one: Does the syntactic/semantic difference between the two constructions trigger a BOLD response in LIFG? Question two: Do the anomalous sentences increase activation in LIFG relative to nonanomalous sentences? And finally, question three: Can the error signal be disentangled from the processing signal? Our results indicate that the answer to the two first questions is "yes", whereas the answer to the last is both "yes" and "no", depending on the measure.

In the behavioral results, acceptability ratings revealed a strong interaction effect of verb type and construction type. This reflects the effects of sentence anomaly. There was no effect of construction type 
Table 3

Main effects and interactions, All p-values corrected for multiple comparisons $(p<0.05 \mathrm{FWE})$.

\begin{tabular}{|c|c|c|c|c|c|}
\hline Contrast & Cluster size (voxels) & Peak P-value (FWE) & Peak Z-value & Peak MNI & Region \\
\hline \multicolumn{6}{|l|}{ Whole brain } \\
\hline \multirow[t]{4}{*}{ Visual $>$ Auditory } & 7700 & 0.000 & Inf & $-34,-80,-14$ & L fusiform gyrus \\
\hline & & 0.000 & Inf & $-40,-84,-10$ & L inf. occ. gyrus \\
\hline & & 0.000 & Inf & $-34,-90,2$ & L mid. occ. gyrus \\
\hline & 6 & 0.001 & 5.51 & $-28,-82,-24$ & L cerebellum \\
\hline \multirow[t]{6}{*}{ Auditory $>$ Visual } & 2178 & 0.000 & $\operatorname{Inf}$ & $-60,-8,-2$ & L sup. temp. gyrus \\
\hline & & 0.000 & 6.17 & $-62,-52,8$ & L mid. temp. gyrus \\
\hline & & 0.001 & 5.60 & $-66,-42,6$ & L sup. temp. pole \\
\hline & 3586 & 0.000 & Inf & $60,-2,-6$ & R sup. temp. gyrus \\
\hline & & 0.000 & Inf & $68,-20,-4$ & $\mathrm{R}$ mid. temp. gyrus \\
\hline & & 0.000 & Inf & $50,-34,0$ & $\mathrm{R}$ mid. temp. gyrus \\
\hline Constr. $2>$ Constr. 1 & 1 & 0.045 & 4.69 & $-56,22,26$ & L inf. frontal gyrus (pars tri.) \\
\hline \multirow[t]{9}{*}{ Verb type $\times$ Construction } & 1251 & 0.000 & 7.00 & $-52,30,8$ & L inf. frontal gyrus (pars tri.) \\
\hline & & 0.000 & 6.61 & $-48,22,12$ & $\mathrm{~L}$ inf. frontal gyrus (pars tri.) \\
\hline & & 0.000 & 6.51 & $-44,28,-2$ & L inf. frontal gyrus (pars tri.) \\
\hline & 455 & 0.000 & 6.67 & $-4,8,66$ & L supp. motor area \\
\hline & & 0.011 & 5.04 & $-4,24,42$ & L sup. medial gyrus \\
\hline & 182 & 0.000 & 6.06 & $-54,-2,46$ & L precentral gyrus \\
\hline & & 0.000 & 5.89 & $-46,4,52$ & L mid. frontal gyrus \\
\hline & & 0.015 & 4.98 & $-42,4,42$ & L precentral gyrus \\
\hline & 10 & 0.018 & 4.94 & $-56,-40,6$ & L mid. temp. gyrus \\
\hline Modality $\times$ Verb type & 25 & 0.036 & 5.42 & $-28,0,-20$ & L amygdala \\
\hline \multicolumn{6}{|l|}{$R O I=L I F G$} \\
\hline \multirow[t]{4}{*}{ Constr. $2>$ Constr. 1} & 144 & 0.001 & 4.69 & $-56,22,26$ & L inf. frontal gyrus (pars tri.) \\
\hline & & 0.011 & 4.17 & $-40,14,26$ & L inf. frontal gyrus (pars tri.) \\
\hline & 3 & 0.035 & 3.83 & $-44,14,34$ & L inf. frontal gyrus (pars oper.) \\
\hline & 1 & 0.043 & 3.77 & $-54,30,14$ & L inf. frontal gyrus (pars tri.) \\
\hline
\end{tabular}

on this measure. When looking at response time measures, however, we observed the opposite phenomenon. Here we found a strong effect of construction type, but no effect of anomaly (i.e. no verb type $\times$ construction type interaction). This differentiation of behavioral measures serves as initial evidence for a difference between the effect evoked by the anomalous sentences (i.e. the "error signal") and the effect of the difference in processing cost between the two structurally different constructions (i.e. the "processing signal"). Interestingly, the response time effect is found across two perceptual modalities, despite the fact that there was a randomized interval of 3$7 \mathrm{~s}$ between sentence presentation and response cue during which participants could prepare their response, and it even remains more or less unchanged despite gross differences in acceptability.

As shown in Fig. 4, participants responded faster to examples that were clearly either anomalous or well-formed. Examples in between, i.e. those that were on average less clearly anomalous or well-formed (i.e. slightly 'ambiguous'), required more processing time. Hence, there was no linear relation between acceptability and response time, and this finding supports the disentanglement of processing signal (measured as response time) and error signal (level of acceptability) at the behavioral level. In other words, low acceptability triggering an error signal need not be accompanied by an increase in response time. Conversely, longer response time (processing signal) need not reflect low acceptability or integration difficulty. However, the error signal (acceptability) and the processing signal (response time) are not orthogonal, since there is a non-linear relation between them. In short, the answer to question three, whether we can distinguish between error signal and processing signal, is "yes". The behavioral data suggest that acceptability and response time are distinct or at least separable: Acceptability reflects error, and response time reflects processing cost.

Turning to the fMRI data; as mentioned in the Introduction, it has been argued that LIFG contains three functional subcomponents, namely, pars opercularis involved in syntactic processing, pars triangularis involved in semantic/thematic integration, and pars orbitalis involved in lexical semantic processing. However, the coordinates for the peak voxels (all but one in pars triangularis) in the construction $2>$ construction 1 contrast (the "syntactic effect") and in the verb type $\times$ construction interaction (the "semantic effect") are essentially identical (see Table 3). The interaction effect is compatible with the proposed subdivision, but the construction effect is not; it should have been in pars opercularis.

A direct comparison between the effects in pars opercularis and pars triangularis is not possible due to potential differences in signalto-noise ratios. However, both the effect of anomaly and the effect of construction were found in both areas. Therefore, our results do not support the proposed functional subdivision of LIFG. Both the acceptability (anomalous vs. well-formed) and the construction (Content-Locative vs. Container-Locative) effects were accompanied by increased activation in LIFG, and moreover, in the same parts of LIFG, namely pars triangularis as well as pars opercularis.
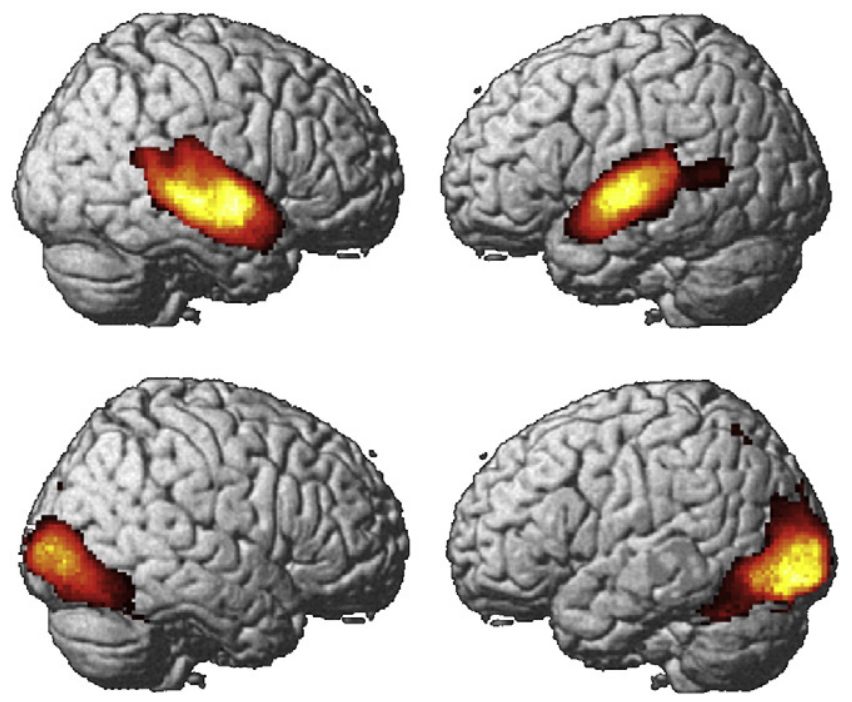

Fig. 5. Top: Auditory condition $>$ Visual condition; bottom: Visual condition $>$ Auditory condition; $p<0.05$, FWE. 

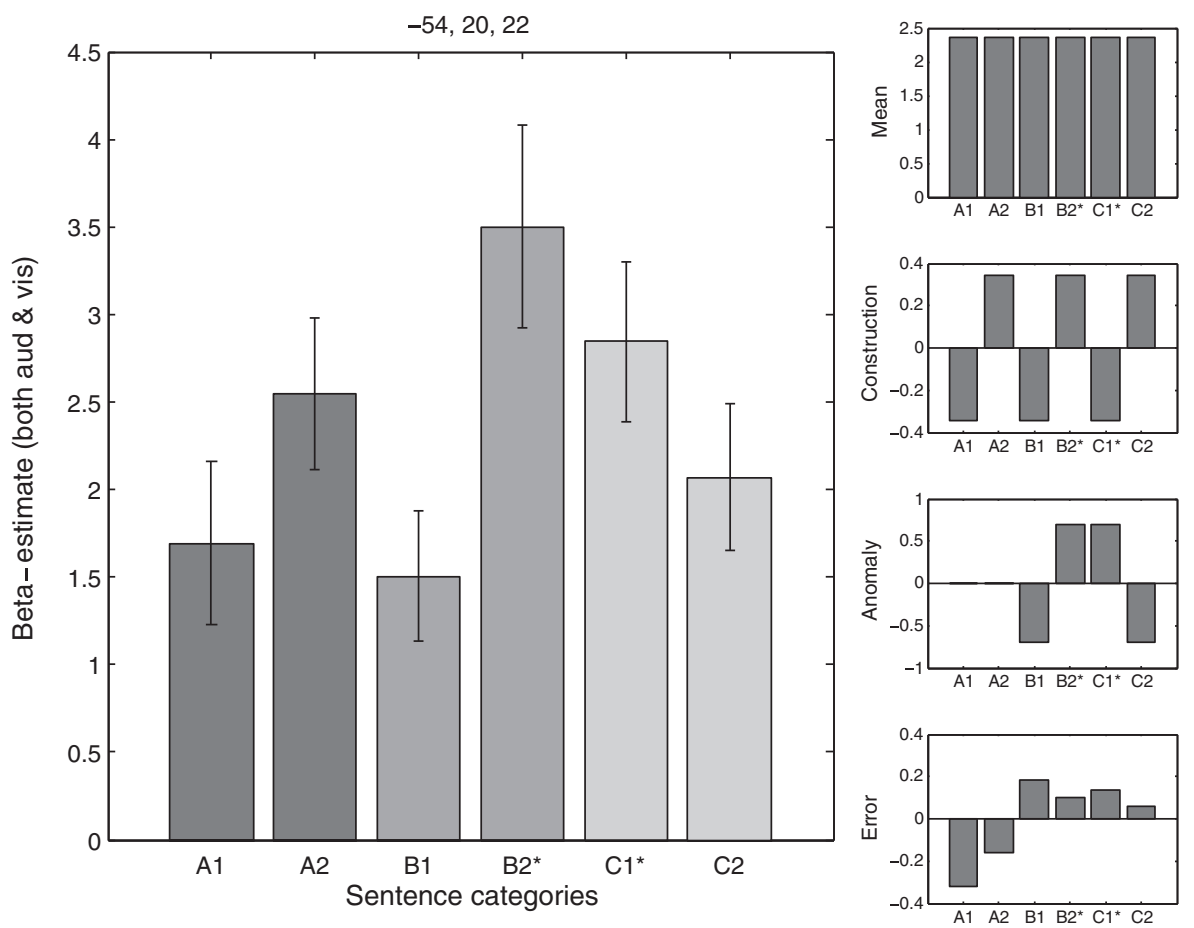

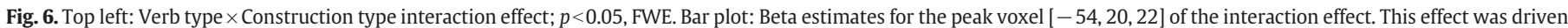
primarily by the main effect of anomaly (i.e. $\left(B 2^{*}+\mathrm{C}^{*}\right)>(B 1+C 2)$ ).

The effect of anomaly, which was the primary trigger for the interaction effect, included a large cluster in the LIFG. The majority of the cluster (71\%) was in pars triangularis, while $16 \%$ was in pars opercularis, and $8 \%$ in pars orbitalis (plus $3 \%$ in the insula and $2 \%$ in precentral gyrus). The fact that pars triangularis was engaged is in line with the results from other studies of semantic anomalies (see Introduction) (though results and inferences vary, see Lindenberg et al., 2007); in particular, the result is consistent with Cardillo et al.'s (2004) hypothesis that LIFG is involved in the inhibition of interference from prepotent representations in the selection of taskrelevant representations. Our results are compatible with Novick et al. (2005) claim that LIFG as a whole is part of a network of frontal lobe

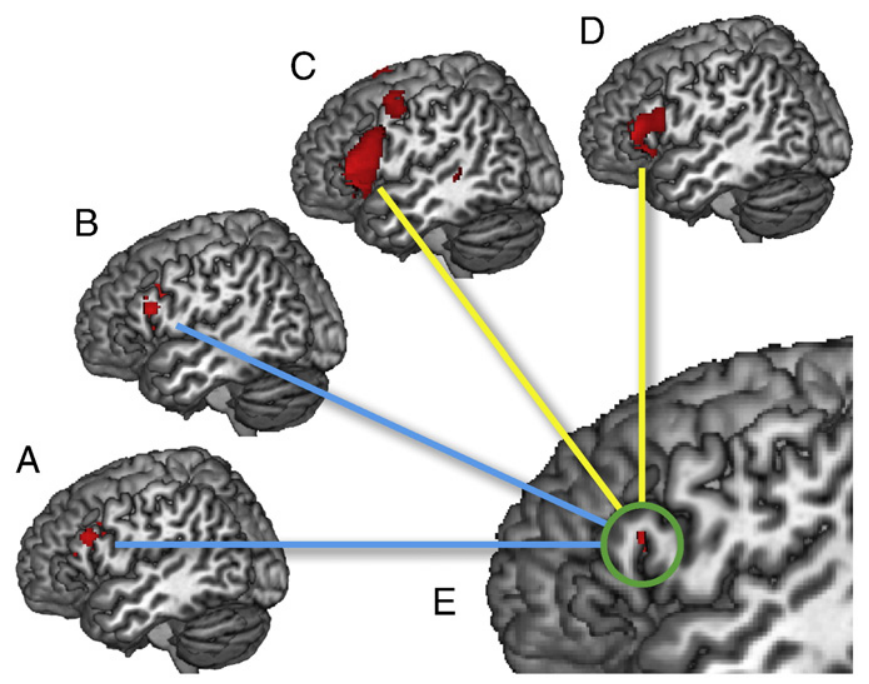

Fig. 7. Surface renderings of fMRI results, $p<0.05$ (FWE corrected for multiple comparisons), sagittal slice $[\mathrm{x}=-54]$. $\mathrm{A}=$ ANOVA Construction effect (ROI $=$ LIFG). $\mathrm{B}=$ Parametric analysis across sentence types with response time from individual participants as input (ROI $=$ LIFG). $\mathrm{C}=$ ANOVA interaction (verb type $\times$ construction). $\mathrm{D}=$ Parametric analysis across sentence types with average acceptability across participants as input $(\mathrm{ROI}=\mathrm{LIFG}) . \mathrm{E}=$ Overlap $[-54,20,22]$ (LIFG pars triangularis). subsystems generally responsible for the detection and resolution of incompatible stimulus representations, for example in Stroop tasks; in particular, the role of LIFG in sentence comprehension is to implement reanalysis in the face of misinterpretation as, for example, in gardenpath sentences where the parser is tricked by a local syntactic ambiguity and a structural bias leading to a globally wrong interpretation. In parsing an anomalous Content/Container-Locative, the bias towards the correct structure must be suppressed in the face of contradicting evidence. For example, in He blocked stones on the road, there is a strong preference for, a prediction of, the NP immediately following the verb to be Container (or Locatum), in turn followed by a PP containing the Content NP. However, the preferred/predicted structural representation must be suppressed

Table 4

One-sample t-tests, $\mathrm{p}<0.05$, FWE, ROI = LIFG. The table shows the negative effect of acceptability (the lower the acceptability rating, the greater the effect) and positive effect of response time (the higher the RT, the greater the effect).

\begin{tabular}{|c|c|c|c|c|c|}
\hline $\mathrm{ROI}=\mathrm{LIFG}$ & $\begin{array}{l}\text { Cluster size } \\
\text { (voxels) }\end{array}$ & $\begin{array}{l}\text { Peak } \\
\text { P-value } \\
\text { (FWE) }\end{array}$ & $\begin{array}{l}\text { Peak } \\
\text { Z-value }\end{array}$ & Peak MNI & Region \\
\hline \multirow[t]{3}{*}{$\begin{array}{l}\text { Acceptability } \\
\text { (neg. effect) }\end{array}$} & 558 & 0.001 & 4.93 & $-54,34,8$ & $\begin{array}{l}\text { L inf. frontal gyrus } \\
\text { (pars tri.) }\end{array}$ \\
\hline & & 0.003 & 4.44 & $\begin{array}{l}-44,26 \\
-4\end{array}$ & $\begin{array}{l}\text { L inf. frontal gyrus } \\
\text { (pars orb.) }\end{array}$ \\
\hline & & 0.007 & 4.26 & $-50,16,14$ & $\begin{array}{l}\text { L inf. frontal gyrus } \\
\text { (pars oper.) }\end{array}$ \\
\hline \multirow[t]{6}{*}{$\begin{array}{l}\text { RT (pos. } \\
\text { effect) }\end{array}$} & 267 & 0.010 & 4.15 & $-40,12,28$ & $\begin{array}{l}\text { L inf. frontal gyrus } \\
\text { (pars oper.) }\end{array}$ \\
\hline & & 0.012 & 4.10 & $-50,18,18$ & $\begin{array}{l}\text { L inf. frontal gyrus } \\
\text { (pars tri.) }\end{array}$ \\
\hline & & 0.018 & 3.96 & $-40,20,26$ & $\begin{array}{l}\text { L inf. frontal gyrus } \\
\text { (pars tri.) }\end{array}$ \\
\hline & 2 & 0.042 & 3.70 & $-44,16,2$ & $\begin{array}{l}\text { L inf. frontal gyrus } \\
\text { (pars tri.) }\end{array}$ \\
\hline & 4 & 0.044 & 3.68 & $-42,16,8$ & $\begin{array}{l}\text { L inf. frontal gyrus } \\
\text { (pars tri.) }\end{array}$ \\
\hline & 1 & 0.048 & 3.65 & $-54,22,26$ & $\begin{array}{l}\text { L inf. frontal gyrus } \\
\text { (pars tri.) }\end{array}$ \\
\hline
\end{tabular}


because the first NP is stones, the Content, followed by a PP containing the Container. This reflects the finding that verb meaning is encoded at two separate levels (Kemmerer and Gonzalez-Castillo, 2010; Pinker, 1989, 2007), a "root" level that differentiates all verbs from each other and an "event structure template" level at which verbs fall into broader categories, such as the Container-Locative and ContentLocative templates. Kemmerer and Gonzalez-Castillo (2010) hypothesize that the processing of verbs at the template level takes place in LIFG (see also Hagoort, 2005), whereas the "root" meaning is distributed to brain regions that process analogous non-linguistic tasks, i.e. motor verbs (e.g. grab, throw, walk, kick, etc.) are thought to be at least partly processed in motor and/or premotor regions of the brain (Pulvermüller, 2001). Unfortunately, Kemmerer and GonzalezCastillo (2010) do not present any hypotheses related to differential processing of different templates.

Under the Linearization Hypothesis (Bornkessel et al., 2005; Bornkessel-Schlesewsky et al., 2009), a main effect of construction (Construction 2>Construction 1) was predicted in pars opercularis, reflecting increased costs as a function of crossed mapping between elements of the thematic hierarchy and the two NPs of the sentences (Fig. 1). This prediction was not borne out in our experiment. Instead, the effect was in pars triangularis and as such our results do not easily support a subdivision of LIFG. Therefore, the present result is compatible with the Linearization Hypothesis, as well as a more general approach under which LIFG is hypothesized to be engaged in detection and resolution of incompatible stimulus representations (cf. Novick et al., 2005, and the discussion above). Moreover, the exact nature of the thematic hierarchy is still debated, and there is little consensus about the number and relative ranking of the roles, beyond ranking AGENT highest (see Levin and Rappaport Hovav, 2005). Leaving out thematic roles irrelevant to the present experiment, some researchers have suggested the following hierarchy AGENT $>$ GOAL $>$ THEME (e.g. Grimshaw, 1990; Van Valin, 1990), others AGENT>THEME> GOAL (e.g. Jackendoff, 1990; Larson, 1988). Nonetheless, regardless of which of the two orders is correct, one of the two constructions in the Locative Alternation will violate the linear order of the hierarchy (see Fig. 1). Hence, the difference between the two constructions would be predicted to trigger LIFG.

Given the greater BOLD response for Construction 2, our findings could be taken as support for the THEME $>$ GOAL interpretation. However, Baker (1997) argues that the thematic roles in the two constructions are not the same. He takes the non-standard view that the Dative Alternation, e.g. give $\left[\mathrm{NP1}=\right.$ THEME $_{\text {a present }}$ to $[\mathrm{NP2}=$ BENEFICIARY someone $]$

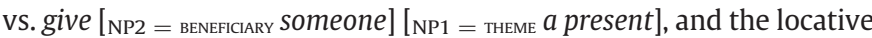
alternation are to be accounted for by different mechanisms. Baker argues that the Dative Alternation involves a syntactic operation deriving $\mathrm{NP}_{2}-\mathrm{NP}_{1}$ from $\mathrm{NP}_{1}-\mathrm{P}-\mathrm{NP}_{2}$ (which itself is non-standard analysis), whereas the Locative Alternation results from two different conceptualizations of the event in question (cf., e.g. Pinker, 1989). Underlying this approach is Baker's Theta Assignment Hypothesis, UTAH, stating that identical thematic relationships between items are represented by identical structural relationships between those items. That basically means that AGENT is in a specific high structural position, THEME in an intermediate position, and GOAL in the lowest object position. Crucially, assuming the UTAH, the Locative Alternation involves a difference in assignment of thematic role; in both the Content-Locative and the Container-Locative, the NP immediately following the verb is assigned the THEME role, the 'fully affected entity'. If that is correct, then the alternation does not involve crossed mapping and, hence, no LIFG effect would be expected, contrary to the present findings from our Danish sample. The present results therefore support, at least for Danish speakers, the standard analysis of the Locative Alternation (involving a reversal of the order of thematic roles, with THEME $>$ GOAL as the basic order) and crossed mapping (the linearization hypothesis, Bornkessel et al., 2005) as illustrated in Fig. 1.
Another hypothesis about the role of LIFG in syntactic processing is that it is not involved in syntactic processing per se. According to Grodzinsky (Ben-Shachar et al., 2003, 2004; Grodzinsky, 2000; Grodzinsky and Friederici, 2006), the role of LIFG in language is primarily to compute the link between moved phrasal constituent and gaps in the syntactic structure. For example, the object is the structural sister of the verb, e.g. She often pushed [the boy from next door]; in topicalizations and in wh-questions, such as, [The boy from next door], she often pushed _ and [Which boy] did she often push _, the object is displaced to the front of the clause. Under standard linguistic assumptions, however, the Locative Alternation does not involve displacement (see Arad, 2005); they are two different realizations of argument structure, neither of which is derived from the other (but see Larson, 1990). Hence, LIFG activation would be predicted not to differ in the contrast between construction 1 and construction 2, contrary to our findings.

The main construction effect in LIFG is also compatible with more general theories of syntactic working memory. Contrasting clausal centre-embeddings, e.g. The juice [that the child spilled] stained the rug, and corresponding right-branching structures, The child spilled the juice [that stained the rug], have been found to increase activation in LIFG (Just et al., 1996; Stromswold et al., 1996; Inui et al., 1998; Fiebach et al., 2005). That is, the structural complexity in centreembedding increases LIFG activation relative to right-branching structure. The contrast between the two constructions in the Locative Alternation also involves a structural difference, though neither has centre-embedding. Apart from having different linear orders, the Content-Locative and the Container-Locative have different syntactic structures. In the Content-Locative both NPs are part of a FigureGround configuration headed by the preposition in/on (in spray paint on the wall, paint is Figure, the wall is Ground), which is determined by the verb (Svenonius, 2003; Talmy, 2000); that means that both objects are contained in the same constituent subcategorised for by the verb. The exact nature of this constituent is probably not important here; we assume it to be a PP. (It may in fact be a verbless result clause parallel to hammer [the metal flat] and put [someone in prison]). In the Container-Locative, on the other hand, the Content PP is optional (cf. that both spray the wall with paint and spray the wall are grammatical) suggesting that [ ${ }_{\mathrm{PP}}$ with paint] is an adjunct and as such structurally adjoined to the verb phrase [vp spray the wall]. The syntactic structures of the two constructions are given in Fig. 8.

The structure of the Container-Locative does not involve centreembedding, but the structural difference between the two constructions in Fig. 8 is clear. It is a contrast between a structure that is rightbranching, which is preferred under the parsing strategy called Right Association (Kimball, 1973; see also Pritchett, 1992; Fodor and Inoue, 1998), and one that is not. Right Association leads us to favor placing phrases into the most recently processed phrases and, hence, the preference for structures with the fewest open nodes at a time. In the Content-Locative (Fig. 6, left), when processing the NP the wall, only the $\mathrm{P}^{\prime}$ node needs to be kept open for attachment. In the ContainerLocative (Fig. 6, right), on the other hand, both the topmost VP and the PP nodes must be open until the NP paint is attached and the structure
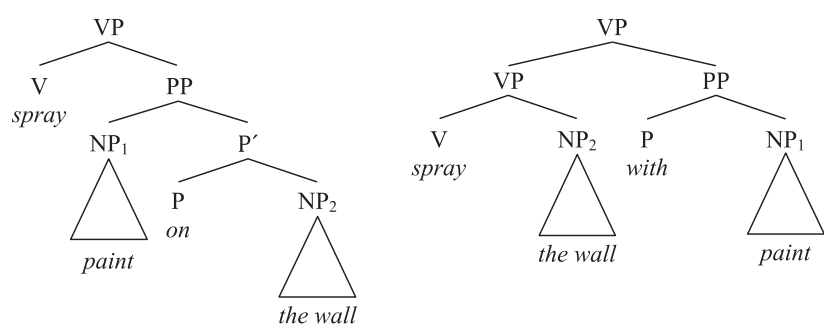

Fig. 8. Left: The structure of the Content-Locative construction (construction 1). Right: The structure of the Container-Locative construction (construction 2). 
is complete. When two possible structures are available, structural ambiguity arises and the parser encounters a so-called garden-path as we mentioned above. The parser has a preference for the rightbranching structure, the Content-Locative, which requires less working memory (structurally defined); the Container-Locative requires a small revision to the structure in order to attach the PP to the VP.

The interaction effect, illustrating the increased processing demands of the anomalous sentences, also included a region in the left precentral gyrus (lateral BA 6) and a bilateral region in the supplementary motor area (SMA, dorsal BA 6), close to (but not including) the anterior cingulate cortex. Premotor cortex (BA 6) has been found to be involved in structure-dependent computation, such as sequential ordering of hierarchical structures in working memory (Christensen, 2010; Hanakawa et al., 2002), and in Stroop tasks (Marshuetz, 2005).

Our third question was whether we could distinguish the effects of anomaly from the effect of increased cost of integration. Our behavioral measures indicated such a distinction, in that we found an acceptability effect for anomaly, but none for the construction contrast whereas we found a response time effect for the construction contrast but none for the anomaly contrast. The two contrasts also resulted in independent activations of LIFG. However, we were not able to separate these into different anatomical locations. In fact, with the spatial resolution of the current experiment, the two activation sites look remarkably similar. This, of course, does not preclude the possibility that the two effects have different generators located within the same anatomical region. But at face value, the present findings are more compatible with an interpretation that LIFG activation, in particular perhaps pars triangularis, is related to overall increased cost of semantic/syntactic integration, whether or not this integration turns out to fail altogether, as was the case with our anomalous sentences. This interpretation is in line with Wallentin et al. (2006) who found that BOLD response to a linguistic stimulus was modulated by response time and overall proficiency in LIFG.

In a study on German word order, Friederici et al. (2006) investigated the cortical effects of ungrammaticality (word order violation) and syntactic complexity in terms of the number of scrambling operations applied to a sentence (scrambling is a type of word-order permutation found in languages such as e.g. German, Dutch, and Japanese). The behavioral results were very similar to the results from the present study. RT increased as a function of complexity, but ungrammaticality yielded shorter RT latencies than the most complex sentences, indicating that ungrammaticality is easier. Their complexity effect observed in LIFG also mirrors ours in the sense that they found a linear increase in BOLD response as a function of complexity but that activation in this region was lower for the ungrammatical. This could be taken to suggest that the complexity effect reported in Friederici et al. (2006) is actually an RT effect. This interpretation is compatible with our suggestion that LIFG activation correlates with increased cost of semantic/syntactic integration. The easier it is to integrate the parts of the sentence or to detect an anomaly, the less activation; conversely, the harder it is, the more activation. The exact localization of the (peak of the) complexity effect, however, is different. This may be due to a number of factors, including individual differences in cortical localization, causing certainty in estimation of peak activation to differ due to differences in sample sizes $(\mathrm{n}=13$ vs. $\mathrm{n}=22$ ), and differences in statistical thresholding (Friederici et al., 2006 used uncorrected p-values, whereas the results reported here are all corrected for multiple comparisons). Friederici et al. also reported effects of ungrammaticality in other regions including the left deep operculum. These additional effects, however, were detected at $p<0.01$ uncorrected and as such could be false positives. However, assuming that the effect was present (but weak), this would be at odds with our findings. It is possible that differences between the languages (German and Danish) used in the two studies or the types of ungrammaticality studied may also have contributed to the differences in neuroimaging results. Further studies are needed to show which results can be replicated.

In summary, the effects of acceptability/anomaly and construction (syntactic complexity) in the present study resulted in independent but inseparable, overlapping LIFG activations compatible with the interpretation that LIFG activation correlates with processing cost (semantic/syntactic integration and anomaly detection). This is also compatible with the findings in Friederici et al. (2006).

\section{Conclusions}

The experiment was based on three research questions. Question one: Is there a BOLD response in LIFG reflecting syntactic processing due to the difference in syntactic structure between the two constructions in the Locative Alternation, i.e. a main effect of construction? Question two: Do anomalous conditions in themselves trigger LIFG? Question three: Can the error signal be disentangled from the processing signal in LIFG? In short, the answer to the two first questions is "yes", whereas the answer to the last is both "yes" and "no".

There was a main effect of construction (Container-Locative $>$ Content-Locative) in LIFG. This effect is compatible with the hypothesis that LIFG is involved in computation of syntactic/semantic structure in general, and that there is a structural difference between the two constructions. In particular, the result is compatible with the Linearization hypothesis (Bornkessel-Schlesewsky et al., 2009) according to which LIFG is involved in the mapping between various linguistic hierarchical structures (sentence structure, thematic hierarchies, etc.), and that crossed mapping results in increased activation in LIFG.

There was a construction-by-type interaction effect in LIFG showing that the main effect of construction is modulated by verb type, i.e. whether a verb is compatible with one or the other construction or both. Using the wrong construction renders the sentence anomalous and gives rise to increased activation in LIFG. This effect is compatible with the hypothesis that LIFG is involved in semantic integration or, more generally, in the detection and resolution of incompatible stimulus representations (Novick et al., 2005).

The fact that there was an interaction between construction and verb type, i.e. syntax and whether or a not a particular verb can occur in both constructions, shows that the effect of processing (the construction effect) and the error signal (anomalous sentences) can be disentangled. The effects are additive, and you can have one without the other. These effects may still, of course, originate in the same generator, linked to overall integration costs. The similarity of localization lends some support to this interpretation.

Supplementary materials related to this article can be found online at doi:10.1016/j.neuroimage.2011.02.081.

\section{Acknowledgments}

This study was supported by grants from the Danish Ministry of Science, Technology and Innovation and The Carlsberg Foundation. The authors wish to thank Douglas Saddy (Centre for Integrative Neuroscience and Neurodynamics (CINN), University of Reading) for comments during the work on the manuscript.

\section{References}

Arad, M., 2005. The spray/load alternation. In: Everaert, M., van Riemsdijk, H. (Eds.), The Blackwell Companion to Syntax. Blackwell, Oxford. Chapter 63.

Baker, M.C., 1997. Thematic roles and syntactic structure. In: Haegeman, L. (Ed.) Elements of Grammar. Handbook of Generative Syntax. Kluwer, Dordrecht, pp. 73-137.

Baumgaertner, A., Weiller, C., Büchel, C., 2002. Event-related fMRI reveals cortical sites involved in contextual sentence integration. Neuroimage 16, 736-745. 
Ben-Shachar, M., Hendler, T., Kahn, I., Ben-Bashat, D., Grodzinsky, Y., 2003. The neura reality of syntactic transformations: evidence from fMRI. Psychol. Sci. 14 (5), 433-440.

Ben-Shachar, M., Palti, D., Grodzinsky, Y., 2004. Neural correlates of syntactic movement: converging evidence from two fMRI experiments. Neuroimage 21, 1320-1336.

Bookheimer, S., 2002. Functional MRI of language: new approaches to understanding the cortical organization of semantic processing. Annu. Rev. Neurosci. 25, 151-188.

Bornkessel, I., Zysset, S., Friederici, A.D., von Cramon, Y., Schlesewsky, M., 2005. Who did what to whom? The neural basis of argument hierarchies during language comprehension. Neuroimage 26, 221-233.

Bornkessel-Schlesewsky, I., Schlesewsky, M., von Cramon, Y., 2009. Word order and Broca's region: evidence for a supra-syntactic perspective. Brain Lang. 111, 125-139.

Cardillo, E., Aydelott, J., Matthews, P., Devlin, J., 2004. Left inferior prefrontal cortex activity reflects inhibitory rather than facilitatory priming. J. Cogn. Neurosci. 16 (9), 1552-1561.

Christensen, K.R., 2008. Interfaces, syntactic movement, and neural activation: a new perspective on the implementation of language in the brain. J. Neurolinguist. 21 (2), 73-103.

Christensen, K.R., 2010. Syntactic reconstruction and reanalysis, semantic dead ends, and prefrontal cortex. Brain Cogn. 73 (1), 41-50.

Dapretto, M., Bookheimer, S., 1999. Form and content: dissociating syntax and semantics in sentence comprehension. Neuron 24, 427-432.

Fiebach, C., Schlesewsky, M., Lohmann, G., von Cramon, D.Y., Friederici, A.D., 2005. Revisiting the role of Broca's area in sentence processing: syntactic integration vs. syntactic working memory. Hum. Brain Mapp. 24, 79-91.

Fiebach, C.J., Vos, S.H., Friederici, A., 2004. Neural correlates of ambiguity in sentence comprehension for low and high span readers. J. Cogn. Neurosci. 16 (9), 1562-1575.

Fodor, J.D., Inoue, A., 1998. Attach anyway. In: Fodor, J.D., Ferreira, F. (Eds.), Reanalysis in Sentence Processing. Kluwer, Dordrecht, pp. 101-141.

Friederici, A.D., 2002. Towards a neural basis for auditory sentence processing. Trends Cogn. Sci. 6 (2), 78-84.

Friederici, A.D., Rüschemeyer, S.-A., Hahne, A., Fiebach, C.J., 2003. The role of left inferior frontal and superior temporal cortex in sentence comprehension: localizing syntactic and semantic processes. Cereb. Cortex 13 (2), 171-177.

Friederici, A., Fiebach, C.J., Schlesewsky, M., Bornkessel, I.D., von Cramon, D.Y., 2006 Processing linguistic complexity and grammaticality in the left frontal cortex. Cereb. Cortex 16, 1709-1717.

Grewe, T., Bornkessel, I., Zysset, S., Wiese, R., von Cramon, D.Y., Schlesewsky, M., 2005. Emergence of the unmarked: a new perspective on the language-specific function of Broca's area. Hum. Brain Mapp. 26, 178-190.

Grimshaw, J., 1990. Argument Structure. MIT Press, Cambridge MA.

Grodzinsky, Y., 2000. The neurology of syntax: language use without Broca's area. Behav. Brain Sci. 23 (1), 1-71.

Grodzinsky, Y., Friederici, A.D., 2006. Neuroimaging of syntax and syntactic processing Curr. Opin. Neurobiol. 16, 240-246.

Hagoort, P., 2005. On Broca, brain, and binding: a new framework. Trends Cogn. Sci. 9 (9), 416-423

Hagoort, P., Hald, L., Bastiaansen, M., Petersson, K.M., 2004. Integration of word meaning and world knowledge in language comprehension. Science 304, 438-441.

Halgren, E., Dhond, R.P., Christensen, N., Van Petten, C., Marinkovic, K., Lewine, J.D., Dale, A M., 2002. N400-like magnetoencephalography responses modulated by semantic context, word frequency, and lexical class in sentences. Neuroimage 17, 1101-1116.

Hanakawa, T., Honda, M., Sawamoto, N., Okada, T., Yonekura, Y., Fukuyama, H., et al., 2002. The role of rostral Brodmann area 6 in mental-operation tasks: an integrative neuroimaging approach. Cereb. Cortex 12, 1157-1170.

Inui, T., Otsu, Y., Tanaka, S., Okada, T., Nishizawa, S., Konishi, J., 1998. A functional MRI analysis of comprehension processes of Japanese sentences. Neuroreport 9 , $3325-3328$.

Jackendoff, R.S., 1990. Semantic Structures. MIT Press, Cambridge MA.

Just, M.A., Carpenter, P.A., Keller, T.A., Eddy, W.F., Thulborn, K.R., 1996. Brain activation modulated by sentence comprehension. Science 274, 114-116.

Kemmerer, D., 2003. Grammatically relevant and grammatically irrelevant features of verb meaning can be independently impaired. Aphasiology 14 (10), 997-1020.

Kemmerer, D., Gonzalez-Castillo, J., 2010. The Two-Level Theory of verb meaning: an approach to integrating the semantics of action with the mirror neuron system. Brain Lang. 112 (1), 54-76.

Kimball, John, 1973. Seven principles of surface structure parsing in natural language. Cognition 2 (1), 15-47.

Kuperberg, G.R., Holcomb, P.J., Sitnikova, T., Greve, D., Dale, A.M., Caplan, D., 2003. Distinct patterns of neural modulation during the processing of conceptual and syntactic anomalies. J. Cogn. Neurosci. 15 (2), 272-293.
Kutas, M., Hillyard, S.A., 1980. Reading senseless sentences: brain potentials reflect semantic incongruity. Science 207, 203-205.

Larson, R.K., 1988. On the double object construction. Linguist. Inq. 19 (3), 335-391.

Larson, R.K., 1990. Double objects revisited. Reply to Jackendoff. Linguist. Inq. 21 (4), 589-632.

Levin, B., 1993. English Verb Classes and Alternations: A Preliminary Investigation. University Of Chicago Press, Chicago.

Levin, B., Rappaport Hovav, M., 2005. Argument Realization. Cambridge University Press, Cambridge.

Lindenberg, R., Fangerau, H., Seitz, R.J., 2007. “Broca's area” as a collective term? Brain Lang. 102, 22-29.

Maess, B., Herrmann, C.S., Hahne, A., Nakamura, A., Friederici, A.D., 2006. Localizing the distributed language network responsible for the N400 measured by MEG during auditory sentence processing. Brain Res. 1096, 163-172.

Maldjian, J.A., Laurienti, P.J., Burdette, J.H., 2004. Precentral gyrus discrepancy in electronic versions of the Talairach atlas. Neuroimage 21, 450-455.

Maldjian, J.A., Laurienti, P.J., Kraft, R.A., Burdette, J.H., 2003. An automated method for neuroanatomic and cytoarchitectonic atlas-based interrogation of fMRI data sets. Neuroimage 19 (3), 1233-1239.

Marshuetz, Christy, 2005. Order information in working memory: an integrative review of evidence from brain and behavior. Psychol. Bull. 131 (3), 323-339.

Mason, R.A., Just, M.A., Keller, T.A., Carpenter, P.A., 2003. Ambiguity in the brain: what brain imaging reveals about the processing of syntactically ambiguous sentences. J. Exp. Psychol. Learn. Mem. Cogn. 29 (6), 1319-1338.

Newman, S.D., Just, M.A., Keller, T.A., Roth, J., Carpenter, P.A., 2003. Differential effects of syntactic and semantic processing on the subregions of Broca's area. Cogn. Brain Res. 16, 297-307.

Novick, J.M., Trueswell, J.C., Thompson-Schill, S.L., 2005. Cognitive control and parsing: reexamining the role of Broca's area in sentence comprehension. Cogn. Affect. Behav. Neurosci. 5 (3), 263-281.

Osterhout, L., Nicol, J., 1999. On the distinctiveness, independence, and time course of the brain responses to syntactic and semantic anomalies. Lang. Cogn. Process. 14 (3), 283-317.

Pinker, S., 1989. Learnability and Cognition. MIT Press, Cambridge MA

Pinker, S., 2007. The Stuff of Thought. Language as a Window into Human Nature. Viking, New York.

Pritchett, B.L., 1992. Grammatical Competence and Parsing Performance. The University of Chicago Press, Chicago.

Pulvermüller, F., 2001. Brain reflections of words and their meaning. Trends Cogn. Sci. 5 (12), 517-524.

Röder, B., Stock, O., Neville, H., Bien, S., Rösler, F., 2002. Brain activation modulated by the comprehension of normal and pseudo-word sentences of different processing demands: a functional magnetic resonance imaging study. Neuroimage 15, 1003-1014.

Saddy, D., beim Graben, P., Drenhaus, H., Frisch, S., 2004a. Distinguishing process from content in language processing: a new answer to an old question. In: Boccaletti, S., Gluckman, B., Kurths, J., Pecora, L.M., Meucci, R., Yordanov, O. (Eds.), Proceedings of the 8th Experimental Chaos Conference (ECC). American Institute of Physics, Melville (NY), pp. 94-105.

Saddy, D., Drenhaus, H., Frisch, S., 2004b. Processing polarity items: contrastive licensing costs. Brain Lang. 90, 495-502.

Stowe, L.A., Broere, C.A.J., Paans, A.M.J., Wijers, A.A., Mulder, G., Vaalburg, W., Zwarts, F., 1998. Localizing components of a complex task: sentence processing and working memory. Neuroreport 9 (13), 2995-2999.

Stromswold, K., Caplan, D., Alpert, N., Rauch, S., 1996. Localization of syntactic comprehension by positron emission tomography. Brain Lang. 52, 452-473.

Svenonius, P., 2003. Limits on P: filling in holes vs. falling in holes. Nordlyd 31 (2), $431-445$.

Talmy, L., 2000. Toward a Cognitive Semantics, Vol I: Concept Structuring Systems. MIT Press, Cambridge MA

Tzourio-Mazoyer, N., Landeau, B., Papathanassiou, D., Crivello, F., Etard, O., Delcroix, N., Mazoyer, B., Joliot, M., 2002. Automated anatomical labelling of activations in SPM using a macroscopic anatomical parcellation of the MNI MRI single-subject brain. Neuroimage 15 (1), 273-289.

Van Valin Jr., R.D., 1990. Semantic parameters of split intransitivity. Language 66, 221-260.

Wallentin, M., 2009. Putative sex differences in verbal abilities and language cortex: a critical review. Brain Lang. 108 (3), 175-183.

Wallentin, M., Roepstorff, A., Glover, R., Burgess, N., 2006. Parallel memory systems for talking about location and age in precuneus, caudate and Broca's region. Neuroimage 32 (4), 1850-1864.

Willems, M.R., Özyürek, A., Hagoort, P., 2007. When language meets action: the neural integration of gesture and speech. Cereb. Cortex 17, 2322-2333. 